Est Ag 52 (2017) 93-121

\title{
Profecía por correspondencia. La carta del profeta Jeremías a los deportados (Jr 29)
}

\author{
José Andrés SÁnchez AbArrio
}

RESUMEN: La progresiva caída del reino de Judá en manos del imperio babilonio, con las sucesivas deportaciones, dio origen a la etapa más crítica y a la vez fecunda de la religión de Israel. La primera reacción entre los deportados fue la desesperación y el lamento. Sin embargo, el exilio fue interpretado por el profeta Jeremías como un acontecimiento en los planes de Dios. El pueblo debe vivir con intensidad este tiempo doloroso dispuesto por Dios. Para ello deben reconstruir sus vidas asentándose en Babilonia, en espera de que Dios ponga fin al exilio y renazca un nuevo pueblo. El profeta Jeremías, desde Jerusalén, hace oír su voz entre los deportados a través de una carta. Dicha misiva y la reacción que creó en la comunidad en el exilio han quedado reflejadas en el capítulo 29 del libro de Jeremías que constituye un excepcional testimonio bíblico de profecía por correspondencia.

Palabras Clave: Carta profética, deportación, exilio, falsos profetas, Jeremías 29.

ABSTRACT: The progressive fall of the kingdom of Judah into the hands of the Babylonian empire, with successive deportations, gave rise to the most critical and at the same time prolific stage of the religion of Israel. The first reaction among those deported was despair and regret. However, the exile was interpreted by the prophet Jeremiah as an event in God's plans. The people must live this painful time prepared by God with intensity. For this they must rebuild their lives by settling in Babylon, waiting for God to end the exile and allow the people to be born again. The prophet Jeremiah, from Jerusalem, makes his voice heard among those deported through a

* Con reconocimiento y gratitud al recordado prof. Senén Vidal, que en el curso 1994-95 me inició en el amor a la Escritura en las aulas del Estudio Teológico Agustiniano de Valladolid. 
letter. This letter and the reaction he created in the community in exile have been reflected in chapter 29 of the book of Jeremiah which constitutes an exceptional Biblical testimony of prophecy by correspondence.

KEYWORDS: prophetic letter, deportation, exile, false prophets, Jeremiah 29.

La época del exilio en Babilonia es quizás la que más ha atraído la atención en los últimos años dentro de los estudios bíblicos. No en vano ha sido la etapa que ha puesto las bases del judaísmo y de la construcción de la Torá. En febrero de 2015 se inauguraba en el Museo de las Tierras Bíblicas de Jerusalén la exposición "By the Rivers of Babylon", curada por Filip Vukosavović, donde se mostraban, entre otros objetos, unas cien tablillas de arcilla del archivo Al-Yahudu (nombrado así por la ciudad donde los exiliados se establecieron en el sur de Iraq), que muestran evidencia de la vida de los exiliados ${ }^{1}$. Para la fecha de las tablillas, 572-477 a.C., la comunidad judía ya se encuentra asentada y los textos atestiguan un considerable nivel de integración: siguen las leyes del imperio, pagan impuestos y viven integrados con otros grupos étnicos.

Pero el camino a esta integración no fue fácil. Para adentrarse en la experiencia del exilio, que abarca desde el 597 a.C. con la primera deportación hasta el 538 a.C., con la vuelta de los israelitas a Judá, debemos servirnos de los datos que nos aportan la historia, la arqueología, la sociología, la literatura y la teología, pues el fenómeno debe ser contemplado desde diferentes perspectivas.

El objeto de nuestro trabajo no es el estudio completo del fenómeno del exilio, sino mostrar un testimonio literario y teológico de los primeros momentos de la deportación que ha quedado en la Biblia: el capítulo 29 del libro de Jeremías. Se trata de un texto peculiar, en un momento muy particular del pueblo de Israel. El profeta Jeremías durante el exilio sigue ejerciendo su ministerio no solo en Judá, donde se encuentra, sino también entre los deportados, la parte del pueblo que ha sufrido el castigo de Nabucodonosor. Para hacer llegar su voz a Babilonia el profeta se sirve de la palabra escrita en forma de carta. Nuestro capítulo recoge, como ve-

${ }^{1}$ El archivo Al-Yahudu está compuesto por más de 200 tablillas, que emergieron en el mercado de antigüedades a principios de los años 70 y que actualmente pertenecen a la colección de David Sofer. Cf. Pearce, L.E. - Wunsch, C., Documents of Judean Exiles and West Semites in Babylonia in the Collection of David Sofer (=CUSAS 28), Bethesda, Maryland 2014; catálogo de la exposición: Vukosavovic, F., By the Rivers of Babylon. The Story of the Babylonian Exile, Bible Lands Museum, Jerusalem 2015. 
remos, algo de la comunicación epistolar que se estableció entre Jerusalén y Babilonia.

El capítulo presenta varias dificultades. No nos encontraremos con una carta entera, ni siquiera con una colección de cartas perfectamente ordenadas. La redacción final de Jr 29 nos ofrece una composición formada por mensajes de Jeremías a los deportados en forma de carta. A tenor del texto, Jeremías, por medio de los mensajeros del rey, hace llegar una carta a los deportados a Babilonia. En ella les exhorta a asentarse en Babilonia y no soñar con un inmediato retorno. El mensaje tuvo que caer como un jarro de agua fría entre los deportados, pero también entre los que permanecieron en Judá. A ambos grupos el profeta les anuncia los "planes de Dios": a los que quedaron en Jerusalén, "espada, hambre y peste" porque rechazan la palabra del profeta; y a los deportados un exilio que durará setenta años. A la carta de Jeremías reacciona un "falso profeta", Semaías, que se encuentra entre los deportados, con otra carta a Sofonías, un sacerdote de Jerusalén, pidiéndole que reprenda a Jeremías. Sofonías lee la carta de Semaías a Jeremías y Yahveh hace responder a Jeremías contra Semaías con otra misiva.

Este puede ser el resumen de lo que nos vamos a encontrar, pero debemos acercarnos al texto con mucha atención y prestar especial cuidado a las marcas textuales, pues nos encontramos con el resultado final de una amplia labor redaccional.

\section{Ambientación histórica}

La muerte trágica del rey Josías marca el inicio del final del reino de

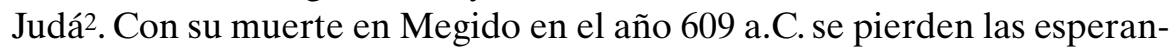
zas de una renovación nacional y religiosa. El faraón Necao no acepta a Joacaz, el gobernante que el pueblo de Judá ha elegido para suceder a Josías

2 Para profundizar en el marco histórico de esta época, cf. VEEN, Peter van der, "The Fall of Jerusalem, the Exile, and the Return", en Arnold, B. T. - Hess R. S. (eds.), Ancient Israel's History. An Introduction to Issues and Sources, Grand Rapids, MI 2014, 383-405; VARO F., "Historia social y religiosa de Israel en los tiempos bíblicos", en CARBAjosa, I. - GonZÁlez Echegaray, J. - VARo F. (eds.), La Biblia en su entorno (=Introducción al Estudio de la Biblia 1), Estella (Navarra) 2013, 259-312; Guevara LlaGunO, J., "El exilio y la diáspora: ¿Israel sin templo?”, en Theologica Xaveriana 62 n 174 (2012) 379-398; Albertz, R., Die Exilszeit. 6. Jahrhundert v. Chr (=Biblische Enzyklopädie 7), Stuttgart 2001 [AlberTz, R., Israel in Exile. The History and Literature of the Sixth Century B.C.E (=SBL 3), Atlanta, GA 2003]; Lipschitz, O., The Fall and Rise of Jerusalem. Judah under Babylonian Rule, Winona Lake, ID 2005. 
y que duró tres meses en el poder. En su lugar, Egipto coloca a Yoyaquín que somete al pueblo a duros impuestos para pagar tributo a Egipto.

En el panorama internacional, la batalla que Carquemis (605 a.C.) marcó el declive del imperio asirio y puso en evidencia el creciente poder en la zona del imperio babilonio en detrimento del dominio egipcio. En medio de esta lucha de imperios, el minúsculo reino de Judá se debate entre qué posición tomar. El profeta Jeremías alza su voz con una llamada a la conversión, pero ni el pueblo ni sus gobernantes quieren escuchar y leer sus palabras (cf. Jr 36).

Entre tanto, Nabucodonosor II llega a Jerusalén para asediarla (2 Re 24,10-17). Según nos relata la Biblia, Yoyaquín se rindió ante él. Nabucodonosor se llevó "los tesoros de la Casa de Yahveh y los tesoros de la casa del rey, rompió todos los objetos de oro que había hecho Salomón, rey de Israel, para el santuario de Yahveh, según la palabra de Yahveh. Deportó a todo Jerusalén, todos los jefes y notables, diez mil deportados; a todos los herreros y cerrajeros; no dejó más que a la gente pobre del país". Y con ellos al rey, su madre, sus mujeres, sus eunucos y los notables del país. La narración bíblica de los hechos tiene su contraparte en las Crónicas Babilónicas3:

En el año séptimo, en el mes de Kislew, el rey de Akkad reunió sus tropas y se puso en marcha hacia el país de Hatti. Puso sitio a la ciudad de Judá; y el día segundo del mes de Adar se apoderó de la ciudad; e hizo prisionero al rey. Designó luego un rey según su corazón y le impuso un fuerte tributo, y lo envió a Babilonia.

Nabucodonosor II coloca como rey vasallo en Jerusalén a Sedecías. A los tres años de la primera deportación y bajo el mandato de Sedecías surgió un grupo religioso nacionalista que pretendía sacudirse el yugo de Babilonia buscando alianzas con Egipto. Este grupo encontró apoyo en familias sacerdotales y altos funcionarios tanto en Jerusalén como entre los deportados. Por el contrario, se organizó también un grupo en torno a la familia de Safán, con el apoyo de Jeremías, que aconsejaba aceptar la sumisión a Babilonia y el castigo merecido, mientras exhortaba a una auténtica conversión ${ }^{4}$. En medio de esta tensión tiene lugar el intercambio de cartas que recoge el capítulo 29 de Jeremías.

3 BM 21946, en Wiseman, D. J., Chronicles of Chaldaean Kings (626-556 b.C.) in the British Museum, London 1956 y más recientemente en GLASSNER, J.-J., Mesopotamian Chronicles (=SBLWAW 19), Atlanta, GA 2004, 230-231.

4 VARO, "Historia social", 287. 
El contexto de la carta que vamos a estudiar podría ser el reflejado en Jr 27,3-7. Emisarios de Edom, Ammon, Tiro y Sidón vienen a Jerusalén para reunirse con Sedecías en un intento de aliarse contra Babilonia. Tal posibilidad pudo avivar el nacionalismo y la esperanza de pronto retorno de los deportados, tanto entre los que se encontraban en Jerusalén como en Babilonia (según Jananías, en dos años volverían, cf. Jr $28,3)^{5}$. La posibilidad de un levantamiento suicida contra Babilonia, pudo estar en la base de la decisión de Jeremías de hacer llegar su palabra a los deportados.

El final es bien conocido. Sedecías desoyó la palabra del profeta y "se rebeló contra el rey de Babilonia" (2 Re 24,20). En el año 589 a.C. Nabucodonosor asedia Jerusalén, castigándola duramente. El rey y los oficiales escapan y se dirigen hacia el valle del Jordán, pero son apresados por las tropas babilonias, que los llevan ante Nabucodonosor, quien somete a juicio al rey. Sus hijos son degollados, y él, después de cegado, es deportado a Babilonia. En el 587 a.C. Nebusardán, jefe de las tropas babilonias, dirige una segunda deportación de población jerosolimitana, incendia el templo y destruye la ciudad. Se cumple así la palabra del profeta.

Sobre la base de los hechos históricos, el fenómeno del exilio puede ser estudiado también desde el impacto causado en la religión de Israel -y desarrollos religiosos posteriores-, hasta su manifestación en la formación de los textos bíblicos. En los últimos años, el fenómeno ha sido objeto de estudio desde el acercamiento sociológico, en cuanto realidad determinante para la vida de un grupo. Los especialistas llaman a este momento coyuntural de Israel "situación de desplazamiento forzoso"6.

5 Bright, J., Jeremiah (=Anchor Bible 21), Garden City, NY 1965, 212, pone en relación este pasaje con Jr 51,50-64b. En 51,59 se indica que el "cuarto año del reinado de Sedecías", Jeremías envía unos mensajes a Babilonia por medio de Seraías, que partió para Babilonia con Sedecías, posiblemente requerido por el rey de Babilonia para mostrarle lealtad. En esta misión diplomática, según Bright, pudo ir la carta de Jeremías. Nos parece difícil de explicar que en la misiva del cap. 29 Jeremías exhorte a asentarse y procurar la paz de Babilonia y, a la vez, según 51,61-64b profetice su destrucción.

6 Para un acercamiento al estudio del Exilio desde una perspectiva sociológica, cf. Kelle, B. E. - Ames, F. R. - Wright, J. L., Interpreting Exile. Displacement and Deportation in Biblical and Modern Contexts (=Ancient Israel and Its Literature 10), Atlanta GA 2011; Aнn, J. J., Exile as Forced Migrations. A Sociological, Literary, and Theological Approach on the Displacement and Resettlement of the Southern Kingdom of Judah (=BZAW 417), Berlin New York, 2010, con abundante bibliografía; SMITH-ChristopHER, D. L., "Reassessing the Historial and Sociological Impact of the Babylonian Exile (597/587-539 BCE)", en SCOTT J. M. (ed), Exile: Old Testament, Jewish, and Christian Conceptions (=Supplements to the Journal for the Study of Judaism 56), Leiden 1997, 7-36. 
J. J. Ahn estudia la realidad del exilio considerando el período que va desde el año 597 a.C., con la primera deportación, hasta el 538 a.C., con la vuelta de los israelitas a Judá (un período de tres generaciones). Este período de tiempo comprende, según el autor, tres olas migratorias: la primera de ellas, en el año 597 a.C. cuando el rey Yoyaquín (Jeconías) es depuesto y Judá se convierte en un reino vasallo de Babilonia. Este fue el primer grupo que constituyó en Babilonia el "enclave étnico". A este primer grupo, el autor denomina DIDPs (development-induced displaced persons). La segunda ola migratoria tuvo lugar en el año 587 a.C., que según J. J. Ahn, no sería propiamente exilio, sino más bien un desplazamiento interno, de la periferia al centro del imperio neobabilonio, pues ya Judá formaba parte del imperio. Identifica a este grupo como IDPs (internally displaced persons). La tercera oleada del año 582 a.C., habría que considerarla también IDP. Todos los deportados durante las tres olas, en el plazo de unos 15 años, formarían la primera generación en el exilio que tuvo que adaptarse a la nueva situación.

Quizás lo más interesante de la propuesta de J. J. Ahn, sea la huella literaria de esta experiencia en la Biblia. Para él, la formación de la primera generación llegó a través de las complejas lamentaciones colectivas. Así, el salmo 137 refleja la situación de desesperación de la primera ola, donde no se pueden quitar a Sión de la mente y el corazón ("A orillas de los ríos de Babilonia estábamos sentados y llorábamos acordándonos de Sión”, v. 1) y el único sentimiento hacia Babilonia es de ira y venganza ("¡Hija de Babel, devastadora, feliz quien te devuelva el mal que nos hiciste, feliz quien agarre y estrelle contra la roca a tus pequeños!”, vv. 89).

El cambio de actitud o la reforma llegó a través del "esperanzado Golah", de lo que él llama la generación 1.5. La generación 1.5 se define como "aquellos que emigraron como adolescentes o pre-adolescentes o, en sentido más amplio, los hijos mayores de padres inmigrantes que fueron capaces de hacer el largo y arduo viaje a pie de Judá a Babilonia"7. Para el autor la generación 1.5 se identificaría con Daniel y sus tres amigos. Jr 29 aparece como el producto de esa generación, exceptuando los vv. 16-20 que serían posiblemente una interpolación de algún editor de la segunda generación. A la generación 1.5 le preocupa la supervivencia y el crecimiento de ambas comunidades en Babilonia y en Judá. La segunda generación y posteriores no tienen interés en volver. La transformación definitiva que llevó a asentarse se alcanzó gracias a la asimilación por

\footnotetext{
7 AHN, Exile, 109.
} 
parte de la segunda generación de la realidad del exilio como nueva creación (Is 43).

La carta que Jeremías dirige a la primera generación de los deportados está alumbrando el trabajo que la generación 1.5 deberá hacer: pasar del lamento a la esperanza.

\section{SitUACIÓN Y ESTRUCTURA DEL CAPítulo}

\section{El contexto inmediato del capítulo}

Antes de estudiar el cap. 29 veamos cuál es su posición en el contexto más inmediato. La mayoría de los autores vincula nuestro capítulo a la unidad 27-29, aunque también existen importantes contactos con el cap. 248 .

El tema principal que recorre estos capítulos es el de los "falsos profetas" (cf. 27,10.14.15.16; 28,15; 29,9.21.23.31). Pero lo que hace de ellos una unidad no es solo este motivo sino también el hecho de que 27-28 constituye una trama narrativa y los capítulos $27-29$, en su conjunto, reflejan una estructura literaria unificadora y global ${ }^{9}$. Además, como ha mostrado Overholt toda la estructura de 27-28 revela un paralelismo con el cap. 2910. Los cap. 27-28 reflejan esta estructura: a) mensaje de sumisión al rey de Babilonia (27); b) respuesta negativa a este mensaje en forma de discurso de Jananías y acción simbólica (28,1-12); y c) resolución del conflicto a través de la maldición a Jananías (28,13-17). Una secuencia similar se desarrolla en el cap. 29: a) mensaje de Jeremías de

8 Algunos de los autores que destacan esta unidad son Rudolph, W., Jeremia (=HAT 12), Tubingen ${ }^{3}$ 1968, 172; Holladay, W. L., Jeremiah 2. A Commentary on the Book of the Prophet Jeremiah, Philadelphia, PA 1989, 114; KeOwn, G. L. - SCALISE, P. J. Smothers, T. G., Jeremiah 26-52 (=WBC 27), Dallas, TX 1995, 35-38; Carroll, R. P., Jeremiah, II, Sheffield 2006, 523; OsuJI, A. C., Where is the Truth? Narrative Exegesis and the Question of True and False Prophecy in Jer 26-29 (MT) (=BETL 214), Leuven - Paris Walpole 2010, 266-291, donde estudia los motivos y temas que se repiten en 27-29, si bien incorpora el cap. 26, donde comienza la narración.

9 "The rhetorical effect of this presentation of the material is a rapid volley of prophetic messages that heightens the conflict and combativeness of this section" (YATES, G. E., "The people have not obeyed". A Literary and Rhetorical Study of Jeremiah 2645", Dallas Theological Seminary 1998, 149 en http://works.bepress.com/gary_yates/11/

10 Overholt, T. W., The Threat of Falsehood. A Study in the Theology of the Book of Jeremiah (=SBT 16), London 1970, 29-20. Las referencias temáticas entre 27-28 y 29 se corresponden, aunque, como veremos, la complejidad del cap. 29 deja abiertas algunas cuestiones. La misma división establece Osuji pero desde una perspectiva más narrativa (mensaje, tensión y resolución). Osusi, Where is the Truth?, 268. 
sumisión a Babilonia centrado en la duración del exilio (29,1-14); b) respuesta negativa a este mensaje por parte de profetas opositores $(29,15$. 21-23.26-28); y c) resolución del conflicto a través de la maldición a Ajab y Sedecías $(29,21-23)$ y Semaías (29,30-32). La narración de los cap. 27-28 refleja la oposición al mensaje de Jeremías en la tierra de Judá, mientras que el caps. 29 muestra la oposición a su mensaje entre los deportados.

Por tanto, el cap. 29 con una entidad propia, cierra un bloque literario referido a la falsa y verdadera profecía. Los capítulos que le siguen, 30-33, han sido llamados "libro de la consolación" y forman una completa unidad.

\section{Indicios de estructuración}

Una primera lectura del capítulo pone en evidencia que, a nivel de redacción final, nos encontramos con tres partes: introducción (vv. 1-3), carta (vv. 4-23) y disputa con Semaías (vv. 24-32), como evidencian las marcas textuales. El cambio brusco y directo a segunda persona del v. 24 , unido al waw redaccional, establece una cesura en el capítulo que concluye en el v. 32 (nótese la inclusión del nombre Semaías en vv. 24 y 32) y delimita el texto de la carta (vv. 4-23).

El capítulo se abre con una extensa introducción del redactor que aporta numerosos datos para la exégesis, como veremos más adelante. La introducción inicia presentando lo que será el cuerpo del capítulo "estas son las palabras de la carta" y concluye con la marca que introduce el discurso (לאמר).

En todo el capítulo, así como en la propia carta, hemos de suponer una labor redaccional que ha aunado diversos oráculos referidos a los deportados y que dificulta el análisis de la perícopa. Los límites de la carta vienen establecidos por los elementos propios del género literario. La carta se abre con la fórmula de inicio (v. 4), que contiene el remitente, "Yahveh Sebaot Dios de Israel" y el destinatario "a toda la deportación" y se cierra con la sentencia que equivale a la firma "yo soy sabedor y testigo" (v. 23) ${ }^{11}$.

11 Holladay, estudiando diversas cartas de la época de Jeremías, concluye que en el cap. 29 nos encontramos con las fórmulas típicas del género epistolar. Lo que primero salta a la vista es la "firma": "yo soy sabedor y testigo" (ואנכי היודע וער). LXX recoge sólo la

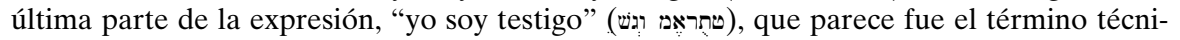
co, mientras que el TM conserva el original y el error escribal (HOLlADAY, W. L., "God 
En el cuerpo de la carta, salta a la vista un primer elemento estructurante que habremos de tener en cuenta a la hora de establecer la estructura de la unidad: la fórmula de mensajero y la fórmula oracular (cf. tabla 2).

Lo que hemos llamado "segunda comunicación" (vv. 24-32) posiblemente agrupe restos de dos misivas, como veremos más adelante: la primera alude a la reacción de Semaías, un "falso profeta" de Babilonia, a la carta de Jeremías; la segunda, la réplica de Jeremías a Semaías dirigida a los deportados. La unidad viene delimitada por la inclusión del nombre ("Semaías, el nejlamita") en los vv. 24 y 32, y cuenta también con fórmulas de mensajero en el v. 25 y en los vv. 31 y 32.

\section{Propuesta de estructura del capítulo}

Las marcas textuales que hemos detectado nos permiten dibujar la estructura general del capítulo (cf. tabla 1). En él nos encontramos dos comunicaciones de Jeremías a los deportados. La primera se trata de una carta del profeta al grupo de los deportados (vv. 4-23), precedida de una introducción (vv. 1-3). La segunda, nos refiere la respuesta de Semaías a la carta de Jeremías (vv. 24-29) y otro mensaje de Jeremías a los deportados a propósito de Semaías (vv. 30-32) ${ }^{12}$.

I. PRIMERA COMUNICACIÓN (vv. 1-23)

A. Introducción (vv. 1-3)

B. Carta (vv. 4-23)

II. SEGUNDA COMUNICACIÓN (vv. 24-32)

A. Acusación contra Semaías (vv. 24-29)

B. Sentencia contra Semaías (vv. 30-32)

Tabla 1

writes a rude letter (Jeremiah 29:1-23)", en Biblical Archaeologist 46 (1983) 145). Para un estudio clásico de las fórmulas epistolares hebreas, véase PARDEE, D. - WhiTEHEAD, J. D. - Dion, P. E., “An Overview of Ancient Hebrew Epistolography”, en Journal of Biblical Literature 97 (1978) 321-346.

12 Esta estructura general es la que adopta OsuJI, Where is the Truth?, 231. SMELIK, K. A. D., "Letters to the Exiles: Jeremiah 29 in Context" en Scandinavian Journal of the Old Testament: An International Journal of Nordic Theology 10:2 (1996) 285-286, dudando que se trata de una carta, prefiere hacer la división del texto según las cuatro profecías: vv. 4-14; vv. 16-19; vv. 20-23; vv. 24-32. 


\section{LA PRIMERA COMUNICACIÓN (Vv. 1-23)}

\section{Introducción (vv. 1-3)}

${ }^{1}$ Estas son las palabras de la carta que el profeta Jeremías envió desde Jerusalén al resto de los ancianos de la deportación, a los sacerdotes y a los profetas y a todo el pueblo que Nabucodonosor había deportado desde Jerusalén a Babilonia, ${ }^{2}$ después de salir de Jerusalén el rey Jeconías y la reina madre, los eunucos, los jefes de Judá y Jerusalén y los artesanos y herreros de Jerusalén, ${ }^{3}$ por medio de Elasa, hijo de Safán, y de Guemarías, hijo de Jilquías, a quienes Sedecías, rey de Judá, envió a Babilonia, donde Nabucodonosor, rey de Babilonia.

La introducción a la carta ofrecida por el redactor nos aporta una abundante información. Comienza por advertirnos del carácter escrito de los oráculos del profeta, las "palabras de la carta" (דברי הספר). Efectivamente, parece que nos hallamos ante el testimonio de una comunicación escrita y no simplemente ante un recurso retórico. Las palabras de Jeremías deben salvar la distancia entre Jerusalén y Babilonia y solo es posible a través de un medio, el escrito. Jeremías en este caso hace uso de la escritura para comunicar su palabra. El fenómeno no es extraño a la cultura del Próximo Oriente Antiguo. Las llamadas "cartas proféticas de Mari" datadas en el s. XVIII a.C. son el ejemplo más antiguo que conservamos de comunicación profética escrita. Los diferentes profetas utilizan las tablillas de arcilla para hacer llegar al rey las comunicaciones oraculares recibidas en los templos del reino de Mari cuando no es posible hacerlo directamente, como en el caso de Jeremías ${ }^{13}$. Aunque no hay un acuerdo unánime entre los especialistas acerca de si estamos o no ante una verdadera carta es preferible afirmar que estamos ante una serie de oráculos enviados en forma de carta ${ }^{14}$. En su atención a los exiliados, la

${ }^{13}$ Los textos de Mari están publicados en la serie Archives Royales de Mari (ARM). La mayor parte de los textos proféticos se encuentran en Durand, J. M., Archives Épistolaires de Mari I/1 (=ARM XXVI Recherche sur les Civilisations), Paris 1988, 377-463. Con pequeñas variaciones en el número de textos a incluir, se encuentran disponibles en otras ediciones: CAGNI, L., Le profezie di Mari, Paideia Editrice, Brecia 1995; RoBERTs, J. J. M., The Bible and the Ancient Near East. Collected Essays, Eisenbrauns, Winona Lake, ID 2002, 157-253; Nissinen, M., Prophets and Prophecy in the Ancient Near East (=Society of Biblical Literature 12), Atlanta, GA 2003, nº 1-50. Además, se encuentran a disposición en www.archibab.fr.

14 "A series of prophetic oracles stated... to have been sent as a letter" (PARDEE, D., Handbook of Ancient Hebrew Letters (=SBL.SBS 15), Chico, CA 1982, 177. "The form of the letter is perhaps to be taken seriously. It is not implausible that such a written communication could have been sent from Jesusalem to the exiles in Babylon" (BRUEGGEMANN, 
carta le sirve a Jeremías para llevar a los deportados la palabra de Yahveh que el profeta anunció de viva voz en Jerusalén. El escrito ocupa el lugar del profeta y llega a donde él no alcanza ${ }^{15}$.

De ella conocemos el remitente, Jeremías, y los destinatarios, "al resto de los ancianos de la deportación, a los sacerdotes y a los profetas y a todo el pueblo que Nabucodonosor había deportado"16. También nos proporciona información del lugar desde el que se envía, "desde Jerusalén" y de su destino "a Babilonia"17. La fecha del envío no se menciona explícitamente, pero viene sugerida por el versículo 2, que resulta ser una inserción explicativa: "después de salir el rey Jeconías (םיאיבְנ) y la reina, los eunucos, los jefes de Judá y Jerusalén y los artesanos y herreros de Jerusalén". Si, por los datos que conocemos, van al exilio en el 597 a. C. (2 Re 24,10-17) y consideramos la unidad de los cap. 27-29, esto ocurre en el "cuarto año de Sedecías", es decir, en el 595-594 a.C. Incluso se nos informa del medio empleado: "por medio de Eleasá, hijo de Safán, y de Guemarías, Hijo de Jilquías a quienes Sedecías había enviado a Babilonia, donde Nabucodonosor, rey de Babilonia" (v. 3$)^{18}$.

W., A Commentary on Jeremiah. Exile and Homecoming, Grand Rapids, MI 1998, 256, n. 32). CARroll, Jeremiah, 567, defiende la composición literaria pero niega las posibilidades reales de que existiera tal comunicación. En un estudio reciente, Doering, L., Ancient Jewish Letters and the Beginnings of Christian Epistolography (=WUNT 298), Tübinge 2012, 107, señala que lo que hace de un texto antiguo una "carta" no son las fórmulas epistolares, que pudieron haberse perdido, sino el hecho de servir de medio escrito entre un remitente y un destinatario para suplir la imposibilidad de una comunicación oral. Y este proceder fue empleado por Jeremías para hacer llegar la palabra de Dios a su pueblo deportado (cf. Jr 51,59-64).

15 "This distancing of the reader parallels the separation of the audience in Babylon from Jeremiah's preaching ministry. A written document could go where the prophet could not. God's word was still valid when readfrom a scrolll" (KEOWN - SCALISE SMOTHERs, Jeremiah 26-52, 69).

16 Nótese que la versión griega de los LXX suprime el nombre de Nabucodonosor y

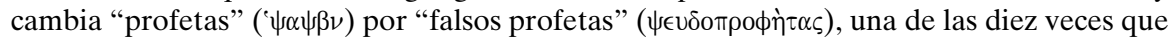
lo hace. Cf. Crenshaw, J. L., Prophetic Conflict. Its Effect Upon Israelite Religion (=Beiheft zur Zeitschrift fur die alttestamentliche Wissenschaft 124), Berlin - New York 1971, 1.

17 Los lugares geográficos adquieren una importancia central en el capítulo. Tal es así que se pueden tener en cuenta para la estructuración del mismo. Jerusalén y Babilonia representan dos situaciones en las que vive el pueblo de Israel, separado por la deportación, que entrarán en relación por medio de la carta. Jerusalén aparece en la introducción 4x; en la carta 2x explícitamente, aunque Yahveh se refiere a ella de diversas maneras: "este lugar" (v. 10), "lugar del que os deporté" (v. 14), "esta ciudad" (v. 16); y en la segunda comunicación 1x. En total: 7x más 3 alusiones. Babilonia aparece en la introducción 3x; en la carta 7x, pero Yahveh se refiere a ella: "la ciudad a la que os deporté" (v. 7); y en la segunda comunicación: 1x. En total: 11x y 1 alusión.

18 Sabemos por 2 Re 22 que Safán y Jilquías tuvieron un papel activo en el descubrimiento del rollo de la Ley que llevó a la reforma de Josías, ocupando los puestos de secretario y sumo sacerdote, respectivamente. 
La relación de esta introducción con la carta viene marcada por el término "deportación" (גלה). Si en la introducción se describen los grupos (resto de los ancianos, sacerdotes, profetas y todo el pueblo) en el incipit de la carta se resume en el intensivo "toda la deportación". Con la segunda comunicación la relación se establece en el v. 28, con la cita explícita a la misma carta: "él nos ha enviado a Babilonia diciendo: "Va para largo, construid casas y habitadlas, plantad huertos y comed su fruto"”.

Un último apunte hemos de hacer antes de pasar a la carta. Aquí el redactor escribe: "a todo el pueblo que Nabucodonosor había deportado", sin embargo, en la carta, cuando Yahveh habla en estilo directo, se presenta como sujeto "yo os deporté" (hif. הגלית) en los vv. 4, 7 y 14. En la concepción de Jeremías, es Yahveh el autor de la deportación, pero no parece que sea así en la del redactor, o quizás haya que ver una pretendida identificación de Nabucodonosor con Yahveh ${ }^{19}$. No en vano en el libro de Jeremías, Nabucodonosor es llamado por Yahveh "mi siervo" $(25,9 ; 27,6 ; 43,10)$. En efecto, el pueblo no escuchó al profeta y Yahveh acude a Nabucodonosor como instrumento para corregir al pueblo ${ }^{20}$.

El envío de la carta nos sitúa en un ambiente de intercambio fluido entre los deportados y el resto que permanece en Jerusalén y que habría que situar en el marco de las relaciones diplomáticas en el Oriente Antiguo. Es posible que esta relación epistolar entre las élites del pueblo fuera consentida por la administración babilonia como una manera de mantener pacíficos a los judíos ${ }^{21}$. Tampoco es de descartar que se tratara de una comunicación más o menos "clandestina", posibilidad que vemos reflejada en la actividad de Semaías en Babilonia y Jananías en Jerusalén 22 .

\section{Carta (vv. 4-23)}

${ }^{4}$ Así dice Yahveh Sebaot, Dios de Israel, a toda la deportación que yo deporté de Jerusalén a Babilonia:

19 J. HiLl, Friend or Foe? The figure of Babylon in the Book of Jeremiah MT (=Biblical Interpretation 40), Leiden - Boston 1999, 146, hace notar que la versión griega de los LXX omite toda referencia a Nabucodonosor en los vv. 1 y 3.

${ }^{20}$ En la concepción bíblica, que Yahveh utilice como instrumento a Nabucodonosor, no quiere decir que apruebe su política. Babilonia será castigada sin remedio (cf. Jr 50-51).

21 Clements, R. E., Jeremiah (=Interpretation. A Bible Commentary for Teaching and Preaching), Atlanta 1988, 171.

22 Ahn, Exile, 137. 
El texto actual de la carta ofrece no pocas dificultades para el análisis. La primera de ellas es determinar la unidad literaria de la carta. Ya hemos indicado que un criterio puede ser el género literario de la composición. Las fórmulas de inicio (v. 4) y de final (v. 23), a modo de firma, nos marcan los límites de la carta. Otros autores prefieren señalar la inclusión, en orden inverso, creada por la fórmula de mensajero: "así dice Yahveh Sebaot, Dios de Israel" (vv. 4 y 21a) y los destinatarios de la carta: "a todos los deportados que yo deporté/envié de Jerusalén a Babilonia" (vv. 4 y 20b) 23.

Para la estructuración interna de la carta contamos con la ayuda de las fórmulas de mensajero y oraculares, aunque éstas no bastarán para resolver los problemas (cf. Tabla 2).

\begin{tabular}{|c|c|}
\hline v. 4 & כה אמר יהוה צבאות אלהי ישראל \\
\hline v. 8 & כה אמר יהוה צבאות אלהי ישראל \\
\hline v. 9 & נחם־יהוה \\
\hline v. 10 & כה אמר יהוה \\
\hline v. 11 & 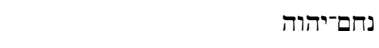 \\
\hline v. 14 & נחם־יהוה (2x) \\
\hline v. 16 & כה אמר יהוה \\
\hline v. 17 & כה אמר יהוה צבאות \\
\hline v. 19 & נחם־יהוה (2x) \\
\hline v. 21 & כה אמר יהוה צבאות אלהי ישראל \\
\hline v. 23 & 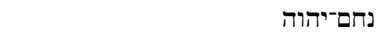 \\
\hline
\end{tabular}

Tabla 2

Debemos atender también a la temática y a la localización espacial. Al incipit de la carta (v. 4) sigue una serie de órdenes a los deportados (vv. 5-7). A éstas sigue una advertencia de no escuchar a los falsos profetas "que están entre vosotros" (vv. 8-9). El v. 10 abre una sección de promesas a los deportados en el nuevo escenario, Jerusalén (vv. 10-14). El v. 15 merece un tratamiento especial; ni puede ir con los precedentes ni con los siguientes (el escenario es Babilonia, no Jerusalén). Se trata de una afirmación de los deportados a la que Yahveh va a responder, como vere-

23 Osus, Where is the Truth?, 235. 
mos en la exégesis. Los vv. 16-19 nos sitúan de nuevo en Jerusalén; Yahveh castigará a los que han permanecido allí. El v. 20 nos lleva de nuevo a Babilonia; si antes les había advertido de no escuchar a los falsos profetas, ahora les exhorta a escuchar a Yahveh. La carta concluye con el anuncio de castigo a los falsos profetas que se encuentran en Babilonia (vv. 21-23). Así las cosas, la estructura de la carta podría ser la siguiente ${ }^{24}$ :

\begin{tabular}{|c|c|}
\hline $\begin{array}{c}\text { A. Órdenes a los deportados (vv. 5-7) } \\
\text { No escuchar a los falsos profetas (vv. 8-9) }\end{array}$ & BABILONIA (Shalom) \\
\hline B. Promesas a los deportados (vv. 10-14) & JERUSALÉN (Shalom) \\
\hline $\begin{array}{c}\text { Afirmación de los deportados (v. 15) } \\
\text { B'. Castigo contra los que quedaron (vv. 16-19) } \\
\text { Escuchar a Yahveh (v. 20) }\end{array}$ & JESUSALÉN (Castigo) \\
\hline $\begin{array}{c}\text { A'. Maldición a los falsos profetas (vv. 21-23) } \\
\end{array}$ & BABILONIA (Castigo) \\
\hline
\end{tabular}

Tabla 3

\section{a. Órdenes a los deportados (vv. 5-7)}

5"Construid casas y habitadlas; plantad huertos y comed su fruto; ${ }^{6}$ tomad mujeres y engendrad hijos e hijas, tomad mujeres para vuestros hijos y dad vuestras hijas a varones para que den a luz hijos e

${ }^{24}$ La división de la carta que hace Osuji es muy semejante a la nuestra, pero no compartimos la centralidad estructural que otorga a las "promesas a los deportados". En su división no se refleja la posición difícil e importante de los vv. 15 y 20 . Une el v. 15 a la unidad 16-19 bajo el título "Fate of those who remained in Jerusalem", aunque más adelante explicará que el v. 15 es una anticipación de los vv. 20-23. Lo que hace con el v. 20 es aún más extraño. Al principio lo une a la unidad 21-23 bajo el título "Oracle of judgement against Ahab and Zedekiak", pero cuando analiza esta unidad encuentra un perfecto quiasmo prescindiendo, claro está, del v. 20. (Ibid., 236). En nuestra estructura hemos preferido respetar la peculiaridad de estos versículos y su posición final en el capítulo y tratar de dar una explicación coherente. A la derecha de la tabla hemos colocado la propuesta 
hijas, multiplicaos allí y no disminuyáis; ${ }^{7}$ procurad el bienestar de la ciudad donde yo os deporté y rezad por ella a Yahveh porque su bienestar será vuestro bienestar."

Esta unidad viene delimitada por la inclusión de la expresión "que yo deporté" (vv. 4 y 7). Narrativamente, estamos en Babilonia. Yahveh se dirige a los deportados que están "en la ciudad a la que os deporté" (v. 7) para indicarles cuál debe ser la actitud de la comunidad en el exilio.

En la unidad se suceden trece imperativos en una cuidada composición literaria. Existe una evolución en las órdenes: necesidades básicas (vivienda, alimento), planes de futuro (procrear y asegurar descendencia) e inserción social (contribución al bien de la sociedad y culto a Dios) ${ }^{25}$. Una evolución que avanza de lo personal a lo social.

La primera serie de órdenes se abre con dos verbos conocidos para el lector de Jeremías. "Construir y plantar" son los verbos utilizados por Yahveh para expresar la misión del profeta en el relato de vocación (cf. Jr 1,10). Dios había puesto sus palabras en la boca del profeta y ahora son las que primero dirige a la comunidad en el exilio. "Construir casa" es asentarse, como lo había hecho el patriarca Jacob tras el encuentro con Esaú: "Jacob partió para Sukkot donde construyó casa para sî" (Gn 33,17). A estos dos verbos les corresponden otros dos imperativos "habitad y comed". Yahveh había prometido "construir y plantar" a los deportados una vez vueltos a su hogar (cf. Jr 24,6) y la expresión sirvió a los profetas para mostrar la acción de Dios tras el exilio (cf. Ez 28,26; 36,36; Is $62,6-9 ; 65,21)$. Lo sorprendente es que ahora les pide que sean ellos los que comiencen a construir y plantar en tierra extranjera ${ }^{26}$.

La segunda serie de órdenes se refiere a la continuidad como pueblo: "Tomad mujeres y engendrad hijos e hijas, tomad mujeres para vuestros hijos y dad vuestras hijas a varones para que den a luz hijos e hijas, multiplicaos allá y no disminuyáis". Aunque no aparece explícito en el texto, lo más probable es que la llamada al matrimonio sea entre los propios miembros del grupo, no con los babilonios. De la existencia de

de J. R. Lundbom, Jeremiah. A Study in Ancient Hebrew Rhetoric (Winona Lake, IND 21997) 137 que nos parece sugerente, aunque tampoco da cuenta de la particularidad de los vv. 15 y 20.

25 Osusi, Where is the Truth?, 237.

${ }^{26}$ March, W. E., "Guess Who Is Coming to Dinner", en Ellens, J. H. - Ellens, D. L. - KNierim, R. P. - KAlimi, I. (eds.), God's Word for our World. Biblical Studies in Honor of Simon John De Vries, I (=JSOT Supplement series 388), London - New York 2004, 204 
matrimonios mixtos tenemos constancia por Es 9-10, pero es poco probable que se dieran en esta primera ola migratoria.

La tarea de crecer y ampliar la comunidad parecía el objetivo una vez vueltos a Judá (Jr 23,3 y 30,19). Pero Jeremías indica, una vez más, que la tarea debe comenzar ya en tierra extranjera, como había pasado en Egipto, cuando los israelitas se multiplicaban (Ex 1,7.30). Babilonia porta la semilla de la renovación, de una nueva creación. Esto es lo que parece indicar la velada referencia a otros dos textos sacerdotales. En efecto, el mandato del v. 6b "multiplicaos" (רבה), con la misma forma de imperativo aparece en otros dos lugares claves de la Biblia, que sin duda guardan relación: la creación y el diluvio. En Gn 1,28 son las primeras palabras que Dios dirige al ser humano: "sed fecundos, multiplicaos y llenad la tierra"27. Tras el diluvio, Dios debe renovar la creación. Bendice a Noé y a sus hijos y les dice: "sed fecundos, multiplicaos y llenad la tierra" (Gn 9,1 y 9,7). La orden de multiplicarse, dada siempre por Dios en la Biblia, guarda relación con el deseo de Dios hacia la humanidad. Al utilizar aquí esta forma, el autor podría estar indicando que se trata de un nuevo inicio. Pero es cierto que, en nuestro texto, no aparece la expresión "llenad la tierra" sino "no disminuyáis". Yahveh quiere garantizar una nueva generación que sobreviva al exilio.

Si la orden de instalarse resultaría escandalosa a oídos de los deportados, cuanto más tuvo que ser la tercera serie de órdenes: "procurad el bienestar" o "la paz" (שלום) de la ciudad28 y "rezad por ella". El versículo contiene un lenguaje propiamente cúltico, "procurar" (דרש) e "interceder" o "rezar" (פלל), que nos sitúa en la esfera de lo religioso.

B. Khato ha hecho notar que la mayor parte de las veces que en el libro de Jeremías se usa el término "paz" (שלום), es en sentido negativo29. Se trata de la "falsa paz" que anuncian los "falsos profetas" basada en el principio de inviolabilidad de Sión y la elección de la dinastía davídica (Sal 89,33-37). Sin embargo, en nuestro caso la invitación es a pedir la paz a Babilonia. El salmista exhorta a pedir la paz para Jerusalén (Sal 122), dentro de sus muros y en sus palacios, pero pedir la paz para Babilonia resultaría a todas luces escandaloso, casi blasfemo. Qué lejos queda aquella sarcástica bienaventuranza del salmista: “¡Hija de Babel, devastadora, feliz quien te devuelva el mal que nos hiciste, feliz quien agarre y estrelle

\footnotetext{
27 Antes, en Gn 1,22 la misma orden fue dada a los animales marinos y a las aves.

28 El término "ciudad" (עיר) del TM, entendido como una sinécdoque, ha sido sustituido en la LXX por "país" ( $\gamma \eta \hat{\varsigma} \varsigma)$.

${ }^{29}$ KATHO, B., "Seek the peace of the city... for in her peace there shall be peace for you (Jeremiah 29: 4-9)", en Old Testament Essays 26 (2013) 348-364.
} 
contra la roca a tus pequeños!" (Sal 137,8-9). Semejante exhortación, ¿es una estrategia utilitarista? ¿se trata de una actitud colaboracionista de Jeremías con el enemigo? ¿o es más bien un plan divino deliberado de hacer vivir al pueblo la experiencia del exilio?30. La invitación a la oración no deja de ser una llamada a mantener la relación con Yahveh, el único que puede salvarles.

La secuencia "construir, plantar, casarse, y procurar el bienestar de la ciudad" aparece en Dt 20,5-1031. Allí aparece en el contexto de la regulación de las exenciones en caso de guerra. El que haya construido una casa nueva y no la haya estrenado todavía, debe volver a ella. También el que haya plantado una viña y no la haya disfrutado, al igual que quien haya desposado una mujer y no se haya casado aún. La razón está en que estas actividades comportan la bendición divina, asociada a la tierra dada por Yahveh. Y, seguidamente, el Deuteronomio ordena que antes de emprender la guerra contra una ciudad, se le proponga la paz. La relevancia de estas actividades queda patente cuando leemos las maldiciones que se derivan del incumplimiento de la alianza: "Te desposarás con una mujer y otro hombre la hará suya; edificarás una casa y no la habitarás; plantarás una viña y no podrás disfrutar de ella" 32 . La alusión de Jeremías a este texto podría tener la intención de alejar toda idea de una posible confrontación con Babilonia. En Is 65,21-23 la actividad de edificar casas y habitarlas, plantar viñas y disfrutar de su fruto y tener descendencia se asocia a la visión profética de la restauración de Israel en Judá.

En suma, con estas órdenes Jeremías les está diciendo que deben abandonar la idea de un inmediato retorno. Construir casas, plantar huertos, engendrar hijos, requiere tiempo. No son proyectos a corto plazo. Con estas órdenes Jeremías tira por tierra la esperanza de una estancia pasajera. La permanencia en Babilonia deben verla como positiva y es allí donde deben reconstruir sus vidas ${ }^{33}$. El profeta lee los acontecimien-

30 "The capacity to entertain both of these affirmations [vv. 5-9 y vv. 10-14] is more than pragmatism, opportunism, and self-interest. Rather, it witnesses a robust dynamic in the textual tradition. It asserts that God has more one thing to do with Judah, and Judah has more than one moment in its destiny" (Brueggemann, A Commentary, 260).

31 Berlin, A. "Jeremiah 29:5-7: A Deuteronomic allusion", en Hebrew Annual Review 8 (1984) 3-11.

32 Sobre el origen y sentido de esta expresión como maldición, cf. SMOAK, J. D., "Building Houses and Planting Vineyards: The Early Inner-Biblical Discourse on an Ancient Israelite Wartime Curse", en Journal of Biblical Literature 127 (2008) 19-35.

33 Holladay, Jeremiah 2, 141. Desde un enfoque sociológico, Ahn hace notar que el establecimiento de un "enclave étnico" sirvió, además, para hacer menos dura la incorporación de las sucesivas olas de migrantes en los años 587 y 582 a.C. (AHN, Exile, 139). 
tos históricos en clave teológica, como lo ha hecho siempre: es en Babilonia donde se van a realizar las bendiciones del Deuteronomio y el lugar donde el pueblo va a recuperar la relación con Dios ${ }^{34}$. En este sentido, Babilonia se identifica con Judá.

\section{b. No escuchar a los falsos profetas (vv. 8-9)}

${ }^{8}$ Así dice Yahveh Sebaot, Dios de Israel: "No os dejéis engañar por vuestros profetas que están entre vosotros y vuestros adivinos, ni hagáis caso de los sueños que soñáis, ${ }^{9}$ porque falsedad os profetizan en mi nombre. Yo no los envié, oráculo del Señor.”

La unidad viene marcada por la fórmula de mensajero, precedida que un introductivo, y por la fórmula oracular con la que concluye. Se introduce el tema de los "profetas y adivinos", pero se une a la perícopa precedente por la continuación de los imperativos, esta vez negativos, "no os engañen", "no escuchéis" y porque sigue hablando a los deportados "que están en medio de vosotros".

Parecería que esta perícopa se ha introducido entre las órdenes (vv. 4-7) y las promesas (vv. 10-14) a los deportados. Con todo, hace referencia a la situación presente en Babilonia. Si antes les ha ordenado de manera positiva lo que deben hacer, ahora les advierte del peligro que corren y de lo que se deben privar. Un peligro que, en este caso, no es externo -como Babilonia- sino que está presente en medio de ellos. Jeremías habla en un tono despectivo de "vuestros profetas" y "vuestros adivinos" que "profetizan falsamente".

El tema de la verdadera y falsa profecía, que aparece por todo el libro, adquiere una importancia particular en la unidad donde se inserta nuestro capítulo (Jr 27-29) ${ }^{35}$. En el capítulo 26, tras el discurso de Jeremías contra el templo, sacerdotes y profetas ponen en duda su profecía (26,11-12). Los jefes y todo el pueblo reconocen que "nos ha hablado en nombre de Dios" $(26,16)$. En el capítulo 28, en el conflicto con el profeta Jananías, Jeremías le reprochará "no te envió Yahveh" (v. 15) y en este mismo capítulo 29 se lo reprochará a Ajab y Sedecías (v. 23) y a Semaías (v. 31). Pues bien, hablar en nombre de Yahveh y ser enviado por Yahveh son las condiciones del auténtico profeta. Jeremías acusó de falso profeta

${ }^{34}$ HiLl, Friend or Foe?, 153.

35 Ver Overholt, T. W., "Jeremiah 27-29: The Question of False Prophecy", en Journal of the American Academy of Religion 35 (1967) 241-249. 
a Jananías, en Jerusalén, y ahora acusa a los falsos profetas que también se hallan entre los deportados. Ellos "profetizan falsedad en mi nombre", pero "yo no los envié". A nivel de significado, esta advertencia de "no escuchar" a vuestros profetas está en contraposición a la exhortación del v. 20, "escuchad" a Yahveh.

La mayoría de los exegetas conviene en afirmar que esa falsedad y esos sueños no serían otros que la esperanza de un pronto retorno. Semejante advertencia de no fiarse de "palabras engañosas" ya había sido formulada por Jeremías años atrás en la puerta del templo de Jerusalén $(7,4.8)$. En aquella ocasión, la falacia reprobable era la falsa confianza en la inviolabilidad del templo a expensas de una conducta inmoral. Jeremías no se ha cansado de denunciar una fe basada en la conveniencia de los hombres más que en la obediencia a Dios.

\section{c. Promesas a los deportados (vv. 10-14)}

10Pues así dice Yahveh: "Cuando se cumplan setenta años en Babilonia yo os visitaré y cumpliré sobre vosotros mi palabra buena para haceros volver a este lugar; ${ }^{11}$ pues yo conozco los pensamientos que tengo sobre vosotros, oráculo del Señor, pensamientos de prosperidad y no de desgracia, de daros un porvenir y una esperanza. ${ }^{12} \mathrm{Me}$ invocaréis y vendréis a rezarme, y yo os escucharé; ${ }^{13}$ me buscaréis y me encontraréis, cuando me busquéis con todo vuestro corazón; ${ }^{14} \mathrm{me}$ dejaré encontrar por vosotros, oráculo del Señor, cambiaré vuestra suerte y os reuniré de todas las naciones y de todos los lugares a los que os arrojé, oráculo del Señor, y os haré volver al lugar de donde os deporté.

La unidad viene definida por la inclusión del verbo "volver" (hif. שוב) y del sustantivo "lugar" (מקום). Precisamente estos serán dos términos que marcarán el sentido de esta perícopa ${ }^{36}$. En vv. 10-14 se produce un cambio de escenario. Es Yahveh el que habla desde "este lugar", es decir, Jerusalén. El tono es bien distinto. Si en los vv. 5-7 Yahveh exhortaba a permanecer en el exilio ahora parece que hace soñar con una situación diferente lejos de Babilonia. Muchos autores ven una contradicción entre los vv. 5-7 y vv. 10-14. Mientras unos lo consideran necesario para contrarrestar la negatividad de los vv. 5-937, otros lo consideran un punto medio entre la resistencia

36 Albertz, R., Israel in Exile, 316, atribuye la perícopa Jr 29,10-14a a la segunda redacción deuteronomista $\left(\mathrm{JerD}^{2}\right)$, compuesta probablemente entre el 545-540 a.C.

37 McKane, W. C., A Critical and Exegetical Commentary on Jeremiah, II, Edinburgh 1986, 738. 
positiva en el exilio y la rebelión que predican los falsos profetas ${ }^{38}$. Quizás lo más simple sea verlo como el anuncio de que el exilio tendrá un fin, cuando Yahveh quiera, pero ahora corresponde vivirlo.

La soberanía de Yahveh se hace manifiesta en todo el texto. Es Yahveh el que ha deportado (vv. 4.7.14.20) pero también el que "hará volver" (vv. 10.14). El שלום/shalom del v. 7 era una tarea de los exiliados, el שלום/shalom que se promete ahora es un don de Yahveh a Judá39. Toda la acción de Yahveh se abre con el verbo "visitar" (פקר), aquí en su sentido positivo, pues reaparecerá al final del capítulo en sentido negativo (v. $32)^{40}$. Entonces, "confirmaré sobre vosotros mi palabra buena", en contraposición a la "palabra falsa" de los profetas. El plan de Yahveh no es arbitrario. El exilio no es un contratiempo para Dios, sino que forma parte de sus planes, así como forma parte la superación del mismo: "conozco los pensamientos que tengo", pensamientos de paz, de porvenir y esperanza. En esta perícopa, de cariz deuteronomista, semejante a Dt 4,29-31 y 30,2-3, asistimos a una intensificación de la relación interpersonal entre el "Yo" de Yaweh y el "tú" del pueblo. El momento en que Yahveh visite a los deportados supondrá un restablecimiento de las relaciones entre Yahveh y su pueblo, como muestra la cuidada construcción literaria de los vv. 11-14. Desaparece la mediación de Babilonia y se establecen unas relaciones directas. Los verbos muestran una relación recuperada $^{41}$. (cf. Tabla 4)

La "visita" de Dios trae el fin del exilio. En el v. 10 se marca el límite: 70 años. Los historiadores han contado 73 años desde la caída de Asiria (612 a.C.) hasta la caída de Babilonia (539 a.C.), pues si contamos el período que va desde el año 597 a.C. (primera deportación) hasta el 538 a.C. (con la vuelta de los israelitas a Judá) no alcanzan los 60 años. En la literatura sapiencial, 70 años es la medida de la vida de un hombre (Sal $90,10)$ y el paso de la tercera a la cuarta generación $(\mathrm{Gn} 15,16)^{42}$. Eso es lo que deberán esperar los oyentes de la carta de Jeremías. Ellos no verán la vuelta, será una nueva generación. Su vida estará marcada por la primera parte de la carta (vv. 5-7) ${ }^{43}$.

\footnotetext{
38 CARroll, Jeremiah 2, 58.

39 Brueggemann, A Commentary, 25.

40 Véase también en expresión muy semejante, pero en sentido negativo, en Jr 25,12.

41 En Babilonia (v. 7), los deportados tenían que rezar "a Yahveh", entonces, en Jerusalén (v. 12), rezarán "a mí".

42 AHN, Exile, 143.

43 En el contexto de 2 Cr 36,5 el período de 70 años tiene un sentido teológico: un tiempo sabático para la tierra. Cf. JAPHET, S., I \& II Chronicles (=The Old Testament Library), Louisville, KY 1993, 1076.
} 


\begin{tabular}{|c|c|}
\hline \multicolumn{1}{|c|}{ Yahveh } & \multicolumn{1}{c|}{ Deportados } \\
\hline $\begin{array}{c}\text { os visitaré } \\
\text { cumpliré } \\
\text { os haré volver } \\
\text { os escucharé } \\
\text { me dejaré encontrar } \\
\text { cambiaré } \\
\text { os reuniré } \\
\text { os haré volver }\end{array}$ & $\begin{array}{l}\text { me invocaréis } \\
\text { vendréis a rezarme }\end{array}$ \\
\hline
\end{tabular}

Tabla 4

Tras la recuperación de la relación (vv. 12-13) viene la salvación formulada en tres expresiones en el v. 14: "cambiaré vuestra suerte", "os reuniré de todas las naciones y de todos los lugares a los que os arrojé" y "os haré volver al lugar de donde os deporté"44. La expresión "cambiar la suerte" es frecuente en los libros de Jeremías y Ezequiel para referirse a la vuelta del exilio. En la redacción final del versículo, la reunión alcanza a dos grupos: los deportados en Babilonia y los dispersos en la diáspora. En el momento final de la redacción del TM, Babilonia se ha convertido en una metáfora o un símbolo del exilio. El hogar, ahora, vuelve a ser Judá45.

\section{d. Afirmación de los deportados (v. 15)}

${ }^{15}$ Puesto que decís: "Nos ha suscitado el Señor profetas en Babilonia".

Ante la dificultad del v. 15, la aparente poca relación con los versículos siguientes, los autores dan diversas respuestas que van desde moverlo a otra posición a considerarlo un error ${ }^{46}$. Ciertamente, el v. 15 encaja

${ }^{44}$ La LXX reduce este versículo a la expresión: "y me mostraré a vosotros" (ка亡 $\epsilon \in \iota \alpha \nu 0 u ̂ \mu \alpha \iota \dot{u} \mu \hat{\imath} \nu)$ del que difícilmente se concluye una referencia al retorno.

45 HiLl, Friend or Foe?, 157.

46 Ver algunas posiciones en OsuJI, Where is the Truth?, 250. 
mejor como introducción a la sección vv. 21-23, como anuncio del cambio de tema (los falsos profetas).

Cualquiera que hubiera sido su posición inicial, ahora lo encontramos entre la promesa a los deportados cuando lleguen a Jerusalén y el castigo a los que quedaron en Jerusalén, y debemos buscar su significado. Este se puede encontrar atendiendo a la posición en la que se encuentra $\mathrm{y}$ al contenido del mismo.

Hasta ahora Yahveh ha hablado de "sus planes" para los deportados (tanto en Babilonia como en Jerusalén, cuando regresen), que son planes de paz. A partir del v. 16 las acciones que Yahveh cumplirá son de castigo, y constituyen la respuesta a los "falsos profetas". Esta respuesta viene motivada por el pensamiento común del pueblo en el exilio que se expresa en el v. 15. Aquí Yahveh cita lo que era vox populi entre los deportados: "nos ha suscitado el Señor profetas en Babilonia" (cf. Jr 28,3-4). Al contenido de esa profecía accedemos por el contexto de nuestro capítulo (Jr 27-29). Su mensaje va en una doble dirección: a) evaluación negativa del exilio; han corrido mejor suerte los que quedaron en Jerusalén; b) consecuentemente predican un inmediato regreso que vendrá como resultado de una revolución. Pues bien, el v. 15 abre paso a la respuesta de Yahveh a estas palabras falsas: los que quedaron no tendrán mejor suerte (vv. 16-19) y los falsos profetas son identificados y castigados (vv. 20-23). Por tanto, al colocar aquí el v. 15, el redactor da paso a la respuesta de castigo de Yahveh ${ }^{47}$.

\title{
e. Castigo contra los que quedaron (vv. 16-19)
}

\begin{abstract}
16Así dice Yahveh acerca del rey que se sienta en el trono de David y acerca de todo el pueblo que habita en esta ciudad, vuestros hermanos que no salieron con vosotros al destierro; ${ }^{17}$ así dice Yahveh Sebaot: "He aquí que voy a enviar contra ellos la espada, el hambre y la peste y los trataré como a los higos podridos que no se pueden comer de malos. ${ }^{18}$ Los perseguiré con la espada, el hambre y la peste y los haré horror para todos los reinos de la tierra y maldición y espanto y burla y oprobio ante todas las naciones por donde los dispersé, ${ }^{19}$ porque no escucharon mis palabras, oráculo del Señor, les envié a mis siervos, los profetas, asiduamente; pero no escuchasteis, oráculo del Señor.
\end{abstract}

47 Ibid., 251. Para KeOwn - SCALiSE - SMOthers, Jeremiah 26-52, 67 el v. 15 presenta los vv. 16-19 como la respuesta de Dios a la afirmación de los exiliados. 
Continúa la carta de Yahveh a los deportados en Babilonia, pero ahora se refiere a los que quedaron en Jerusalén, "en esta ciudad". Los límites de la unidad literaria vienen marcados de nuevo por la fórmula de mensajero (v. 16) y la fórmula oracular (v. 19). En el v. 20 Yahveh deja de referirse a los que quedaron en Jerusalén y se dirige directamente a los deportados. La versión de la LXX omite los vv. 16-20 permitiendo una lectura continua del v. 15 con vv. 21-2348.

El primer destinatario del castigo viene formulado con el epíteto "el rey que se sienta en el trono de David". La misma expresión aparece en 22,2 cuando Jeremías se dirige al palacio del rey Yoyaquín para exhortarle a practicar la justicia y el derecho y así mantener la promesa hecha a David, de lo contrario, la "casa" irá a la ruina. Seguidamente, la acusación recae sobre "todo el pueblo que habita en esta ciudad", es decir, "vuestros hermanos que no salieron con vosotros al destierro"49. Contra estos, enviará el triple castigo anunciado en el cap. 24.

En efecto, los planes de Yahveh para los deportados y para los que quedaron en Jerusalén le fueron mostrados a Jeremías en la visión de los cestos de higos del cap. 24. Las semejanzas textuales con nuestro capítulo son numerosas (cf. Tabla 5).

De esta correspondencia textual con el cap. 24 podemos sacar una consecuencia a nivel narrativo: Yahveh está diciendo ahora a los deportados lo que ya había dicho en Jerusalén a Sedecías, a los sacerdotes y a todo el pueblo de Jerusalén (cf. Jr 27, 12-16). ¿Por qué decir a los deportados la suerte que correrán los que quedaron? Como ya hemos indicado, porque Yahveh quiere dar una respuesta a la falacia suscitada por los falsos profetas entre los deportados (cf. v. 15).

48 Para el debate entre parablepsis u omisión deliberada de esta perícopa, véase Hoop, R. D., "Textual, Literary, and Delimitation Criticism: The Case of Jeremiah 29 in [TM] and [LXX]", en Korpel, M. C. A. -Hoop, R. D. -Porter, S. E. (eds.), The Impact of Unit Delimitation on Exegesis (=Pericope. Scripture as Written and Read in Antiquity 7), Brill, Leiden - Boston 2009, 34-37. Muchos autores consideran los vv. 16-20 como una interpolación posterior, quizás de la comunidad postexílica bajo la autoridad de Ezequiel. Cf. SeITZ, C. R., Theology in Conflict. Reactions to the Exile in the Book of Jeremiah (=Beiheft zur Zeitschrift fur die alttestamentliche Wissenschaft 176), Berlin - New York 1989, 211-212; HolladAY, Jeremiah 2, 135.

49 Según Hill, Friend or Foe?, 148 que considera la perícopa un añadido del redactor deuteronomista, no se estaría refiriendo aquí al resto que quedó en Jerusalén de la primera deportación (597 a.C.) ni siquiera de la segunda (587 a.C.) sino de la tercera (582 a.C.) que buscó refugio en Egipto socavando la voluntad de Dios y la solidaridad con los deportados en Babilonia (cf. Jr 42). 
La acusación contra el rey y los que quedaron en Jerusalén (v. 19) viene expresada en términos de obediencia: éstos "no escucharon mis palabras" enviadas por medio de "mis siervos, los profetas".

\begin{tabular}{|c|c|}
\hline higos malos & $\begin{array}{ll}24,8: & \text { los trataré como a esos higos tan malos que no se } \\
\text { pueden comer } \\
\text { 29,17: } \\
\text { los trataré como a los higos podridos que no se } \\
\text { pueden comer de malos }\end{array}$ \\
\hline destinatarios & $\begin{array}{l}\text { 24,8: rey de Judá ... al resto de Jerusalén que quede en } \\
\text { esta tierra } \\
\text { 29,16: el rey ... todo el pueblo que habita en esta ciudad }\end{array}$ \\
\hline castigo & $\begin{array}{l}\text { 24,9: les haré horror y mal para todos los reinos de la tie- } \\
\text { rra... } \\
\text { oprobio ... ante todos los lugares por donde los dis- } \\
\text { persé } \\
\text { 29,18: les haré horror para todos los reinos de la tierra } \\
\text { oprobio ante todas las naciones por donde los dis- } \\
\text { persé }\end{array}$ \\
\hline triple plaga & $\begin{array}{l}\text { 24,10: enviaré la espada, el hambre y la peste } \\
\text { 29,18: los perseguiré con la espada, el hambre y la peste }\end{array}$ \\
\hline
\end{tabular}

Tabla 5

\section{f. Escuchar a Yahveh (v. 20)}

${ }^{20}$ Vosotros, pues, escuchad las palabras del Señor, todos los deportados que yo envié de Jerusalén a Babilonia”.

La dificultad de encajar este versículo en cualquiera de las unidades que le rodean es evidente. Con la unidad precedente existe una diferencia importante: Yahveh deja de hablar de los que quedaron en Jerusalén y se dirige directamente a los deportados. El cambio brusco viene marcado por el pronombre personal precedido de un waw (ואתם). Pero al mismo tiempo la relación es patente por la cercanía del verbo principal de cada 
frase: al "no escucharon" del v. 19, se corresponde el "escuchad" del v. 20. Con la unidad que le sigue (vv. 21-23) podría tener más relación, si consideramos que la noticia sobre el destino de los dos "falsos profetas" fuera dirigida a los deportados. De hecho, en vv. 21-23 se habla de ellos en tercera persona. Podemos ver este versículo, amén de su historia redaccional, como un paso entre el castigo en Jerusalén y el castigo para los dos profetas que obran en Babilonia a los que se ha referido en el v. 8 .

g. Maldición a los falsos profetas (vv. 21-23)

${ }^{21}$ Así dice Yahveh Sebaot, Dios de Israel acerca de Ajab, hijo de Colayas, y acerca de Sedecías, hijo de Masías que os profetizan falsedad en mi nombre: he aquí que yo los entrego en manos de Nabucodonosor, rey de Babilonia y los herirá delante de vosotros $22 \mathrm{y}$ tomarán de ellos esta maldición todos los deportados de Judá que están en Babilonia: "que el Señor te trate como a Sedecías y a Ajab a quienes asó a fuego el rey de Babilonia", ${ }^{23}$ porque obraron con infamia en Israel y cometieron adulterio con las mujeres de sus prójimos y dijeron palabra falsa en mi nombre que no les mandé. Yo soy sabedor y testigo, oráculo del Señor.

$\mathrm{Al}$ igual que la unidad anterior esta viene marcada por las fórmulas de mensajero (v. 21) y oracular (v. 23), además de la inclusión de la expresión "falsedad en mi nombre". La unidad se subdivide en: acusación (v.21a), castigo-maldición (v. 21b-22), nueva acusación (v. 23a) y firma (v. 23b).

La primera acusación se dirige a dos profetas que obran en Babilonia. De su existencia ya habíamos oído hablar en el v. 8, ahora conocemos sus nombres, Ajab y Sedecías. En primer lugar, se les acusa de profetizar "mentira" y de hacerlo en nombre de Yahveh, una característica típica de los falsos profetas.

El castigo es la muerte, pues serán entregados "en manos de Nabucodonosor", que actúa de nuevo como instrumento de Yahveh. Estos serán objeto de maldición. Aunque estén en Babilonia correrán la misma suerte que los que permanecieron en Jerusalén. Nótese la ironía: los que en el v. 15 se gloriaban de que tenían profetas, acaban usando sus nombres como maldición.

A la acusación del v. 21 se añaden otros tres cargos: "obraron con infamia en Israel", "cometieron adulterio con las mujeres de sus prójimos" y "dijeron palabra falsa en mi nombre que no les mandé". De estas tres acusaciones la más inusual es la segunda, las otras son las propias de 
los falsos profetas ${ }^{50}$. Se trata de una acusación de inmoralidad como denota el término usado (נבלה/nebalah) ${ }^{51}$. Parece que el castigo de ser echado al fuego guarda relación con este último delito. En el Antiguo Testamento se reserva esta pena para el adulterio al menos en otros dos casos (Gn 38,24; Lv 21,9), como viene formulado en la ley de Dt 22,22.

La unidad concluye con lo que hemos llamado "firma" que cierra el cuerpo de la carta.

\section{LA SEGUNDA COMUNICACIÓN (vv. 24-32)}

Hemos agrupado lo que parecen ser dos mensajes de los vv. 24-32 bajo una misma "comunicación". Que se trate de dos mensajes, aunque ciertamente incompletos, parece evidente a juzgar por los diversos destinatarios: el primero de ellos a "A Semaías, el nejlamita" (v. 24) y el segundo a "todos los deportados" (v. 31). El redactor final los ha unido de una manera curiosa. En el primer mensaje, Yahveh, por boca de Jeremías, le informa a Semaías -o más bien al lector- de lo que él mismo ha hecho. De esta manera tenemos noticia de la respuesta de Semaías a la carta precedente de Jeremías (vv. 4-23). Esperaríamos que Yahveh informara a Semaías de su sentencia, pero la carta se corta bruscamente (v. 28). Parece que estos versículos le han parecido suficientes al redactor para su propósito: informar al lector de la reacción de Semaías. La sentencia contra Semaías la conocerán los deportados en una nueva comunicación de Jeremías (vv. 31-32). De nuevo estos versículos le bastan al redactor para su propósito: dar a conocer, no sólo a los deportados sino también al lector, la sentencia contra Semaías.

\section{Acusación contra Semaías (vv. 24-29)}

${ }^{24}$ A Semaías, el nejlamita, dirás: ${ }^{25}$ Así dice Yahveh Sebaot, Dios de Israel: tú enviaste cartas por tu cuenta a todo el pueblo que está en Jerusalén, a Sofonías, hijo del sacerdote Maasías y a todos los sacerdotes diciendo: 26"El Señor te ha nombrado sacerdote al puesto del sacerdote Yehoyadá como responsable del templo del Señor y para que todo el que se desmande y se meta a profetizar le pongas cepo y

50 Sobre la posibilidad real de esta acusación y su relación con las leyendas de Nabucodonosor, véase CARROLL, Jeremiah 2, 560-561.

51 Phillips, A. "Nebalah", en Vetus Testamentum 25 (1975) 237-242. 
argolla. ${ }^{27}$ Entonces, ¿por qué no has reprendido a Jeremías de Anatot que se ha metido a profetizar entre vosotros? ${ }^{28}$ Nos ha enviado a Babilonia (una carta) diciendo: 'Va para largo, construid casas y habitadlas, plantad huertos y comed de su fruto"'. ${ }^{29} \mathrm{El}$ sacerdote Sofonías leyó esta carta al profeta Jeremías.

Yahveh manda a Jeremías comunicar un mensaje a Semaías (v. 24), que se encuentra en Babilonia (v. 25)52. Desconocemos si el término "nejlamita" se refiere a gentilicio o a una familia determinada53. Por tanto, hemos de suponer que se trata de una nueva carta. De ella el redactor nos ha transmitido cuatro versículos, a modo de sumario, los suficientes para darnos a conocer las acciones de Semaías. Así, de un modo indirecto, sabemos de la reacción de Semaías al leer la carta de Jeremías a los deportados. Que se trate de esta carta parece evidente, pues Semaías se refiere a ella con las primeras palabras de la misiva: "construid casas y habitadlas, plantad huertos y comed su fruto" (vv. 5 y 28). Pero a esta cita añade su valoración personal que resumen el efecto que causaron las palabras de Jeremías: "va para largo".

Lo que se le reprocha a Semaías es haber escrito, por su cuenta ${ }^{54}$, cartas (ספרים), a Sofonías, el sacerdote, y a todo el pueblo que está en Jerusalén, y a todos los sacerdotes, advirtiéndoles del peligro que representa Jeremías y exigiéndole poner "cepo y argolla" a todo loco que profetice, cumpliendo así su tarea de sacerdote ${ }^{55}$.

La unidad concluye con el v. 29, que forma inclusión con el v. 25, haciendo referencia a la "carta". El mensaje de Jeremías a Semaías se interrumpe sin que sepamos más. ¿Contenía el resto de la carta la sentencia? Sofonías, hijo de Maasías (Jr 21,1; 37,3), lee a Jeremías la carta de Semaías (v. 29).

52 Según Dijkstra, M. "Prophecy by Letter (Jeremiah XXIX 24-32)", en Vetus Testamentum 33 (1983) 320, el v. 24 no se trata de una instrucción de Yahveh a Jeremías, sino un fragmento de la fórmula de mensajero. La carta se abriría directamente con la referencia a la respuesta de Semaías, por eso sugiere suprimir la fórmula de mensajero: "Así dice Yahveh Sebaot, Dios de Israel".

53 YAURE, L."Elymas-Nehelamite-Pethor", en Journal of Biblical Literuture 79 (1960) 279-314, ha sugerido que pudiera tratarse de una forma nifal participio del verbo hlm (soñar), refiriéndose así a un "soñador", aunque la forma verbal no está atestada en el Antiguo Testamento. Lo cierto es que Jeremías ya ha advertido contra los que sueñan en Babilonia (v. 8).

54 "En tu nombre", es la actuación propia del falso profeta, no del que habla en nombre de Dios.

55 No podemos saber el número de cartas que denota el plural, aunque aquí se quiere destacar la enviada al sacerdote Sofonías. 


\section{Sentencia contra Semaías (vv. 30-32)}

${ }^{30}$ Vino la palabra del Señor a Jeremías diciendo: 31"Envía a decir a todos los deportados: Así dice Yahveh acerca de Semaías, el nejlamita, por cuanto que os profetizó Semaías sin que yo lo enviara y os hizo confiar en la mentira. ${ }^{32}$ Por eso, así dice Yahveh: yo castigaré a Semaías el nejlamita y a su descendencia: nadie de los suyos vivirá en medio de este pueblo y no verá el bien que yo voy hacer a mi pueblo, oráculo del Señor, porque predicó rebelión contra el Señor."

La sentencia contra Semaías nos llega por otra carta que Jeremías escribe "a todos los deportados" o, mejor dicho, por la instrucción que Yahveh le da para que la escriba. De nuevo, Jeremías recibe la "palabra de Yahveh" en contraposición a la palabra mentirosa de los falsos profetas. La sentencia, flanqueada por las fórmulas de mensajero y oracular, consta de acusación (v. 31b) y castigo (v.32).

La acusación es semejante a la hecha contra los falsos profetas: profetizó sin ser enviado e hizo confiar en la mentira. Para ejecutar el castigo Yahveh va a visitar (פקר), usado aquí en sentido negativo, no como en el v. 10. El castigo consiste en que "no tendrá a nadie que viva en medio de este pueblo" ni verá el "bien" que Yahveh va a hacer con su pueblo, la palabra buena o promesa anunciada a los deportados en el v. 10, porque "predicó rebelión contra Yahveh"56. En la concepción profética, rebelarse contra la palabra del profeta es equivalente a rebelarse contra Yahveh. La predicación de Semaías representa la oposición a Yahveh y a su palabra y su figura se coloca, para los deportados, como la figura de Jananías para los habitantes de Jerusalén (cf. Jr 28,15-17) ${ }^{57}$.

\section{Conclusión}

En un texto redaccionalmente complejo como el nuestro, la atención a los elementos estructurales se ha revelado como el camino más apropiado para captar el significado del capítulo y su inserción en el libro.

56 Más adelante, en el llamado "libro de la Consolación”, Jeremías anuncia el fin del antiguo principio de la responsabilidad colectiva por el que los hijos reciben el castigo de los pecados de sus padres (Jr 31,29-30).

57 CARroll, Jeremiah 2, 566. "Shemaiah becomes an opponent of Jeremiah who, following the emphasis of the chapters 26-29, rejects the word of YHWH through his prophet" y ofrece puntos de contacto entre Jananías (Jr 28) y Semaías (Jr 29) (OsuJI, Where is the Truth?, 260). 
Ante la situación de división espacial del pueblo de Israel, el profeta se sirve de una carta para hacer llegar su mensaje, la palabra de Yahveh, a la parte del pueblo que se encuentra deportada en Babilonia. Para ellos tiene un anuncio concreto: deben reconstruir sus vidas asentándose en Babilonia, multiplicarse e incluso rezar por ella, viviendo el exilio al que Yahveh los ha sometido. Esta situación no será perpetua, sino que tiene un plazo. Llegado el día se restablecerán las relaciones entre Yahveh y su pueblo y regresarán a la tierra de Judá.

El tema de los "falsos profetas" que tiene tanta importancia en el libro de Jeremías, y en especial en la sección 27-29, se hace notar como problema también entre los deportados. En este caso la falacia que anuncian es el inmediato retorno a Judá. Jeremías se alza como el auténtico profeta, el que habla "en nombre de Yahveh" una palabra que no siempre es cómoda. El pueblo en el exilio no debe dejarse llevar por el mensaje de los falsos profetas, pues el destino de estos es la muerte.

El significado del texto se intuye entre las tensiones presentes: Babilonia-Jerusalén, escuchar a los falsos profetas-escuchar a Yahveh, shalom-castigo, reunir-dispersar, llevar al exilio-hacer volver del exilio. El tiempo del exilio supone un antes y un después en la fe de Judá y una experiencia de transformación interior.

Mediante la carta Jeremías hace llegar el mensaje que ya anunció en Jerusalén a los deportados. La palabra de Yahveh, por medio de una carta, traspasa los límites de Judá y se hace operante en tierra extranjera. Precisamente fuera de la tierra de Israel, sin templo, el pueblo aprenderá a escuchar la palabra de Dios pronunciada -y escrita- por los profetas. 